\title{
Maker: 3D Printer from Scratch Made with e-Waste
}

\section{William Sarkis Babikian, Vaughn College of Aeronautics \& Technology}

William Babikian is a full-time undergraduate student in the Mechatronics Engineering program at Vaughn College of Aeronautics and Technology. He has experience in applied robotics and automation in assembly lines. His general interests include computer programming, engineering product designing, and pure mathematics.

\section{Terry K Beesoon, Vaughn College of Aeronautics and Technology}

I am a student fourth year student enrolled in a bachelor of science program for mechatronics engineering at Vaughn College of Aeronautics and Technology.

\section{Dr. Shouling He, Vaughn College of Aeronautics \& Technology}

Dr. Shouling He is an associate professor of Engineering and Technology at Vaughn College of Aeronautics and Technology, where she is teaching the courses in Mechatronics Engineering and Electrical Engineering Technology. Her research interests include modeling and simulation, microprocessors and PLCs, control system designs and Robotics. She has published more than 45 journal and conference papers in these research areas.

Dr. Hossein Rahemi, Vaughn College of Aeronautics \& Technology 


\section{D Printer from Scratch Made with e-Waste}

\section{ASTRACT}

In this project we present our idea about building a 3D printer based on the recycled electronic components. The motivations for us to work on the project are (1) 3D printing technology as next industrial revolution has caught wide attention around the world. With the development of the technology, a custom part that would previously take a great deal of time and money for a professional manufacturer to produce can now be made much quicker at a very low cost. Particular for college engineering education, students can produce different innovative parts for their new designs for robots or unmanned aerial vehicles using a self-made 3D printer. Therefore, developing the technique is of significance; (2) Although 3D printers use a variety of types of additive manufacturing technologies, the core action is in common: they create a three dimensional object by building it layer by successive layer, until entire object is complete. Furthermore, most devices required to make each layer of the object are similar to the printers used in last several decades, such as stepper motors, drive train, fans, gears, glass bed and so on. Hence, the 3D printer developed in our project has been fully made use of recycled electronic components, which helps to reduce the cost of a 3D printer and prevent the environmental contamination due to huge amount of e-waste generated in the United States. The practical project allows us to apply the knowledge we learned from different fields in mechatronics engineering: electrical, mechanical, automation, control, and computer engineering. Moreover, it improves our problem-solving and troubleshooting skills.

Keywords: 3D printers, Building, E-Waste.

\section{INTRODUCTION}

A 3D printer is a limited type of industrial robot that is able to carry out an additive

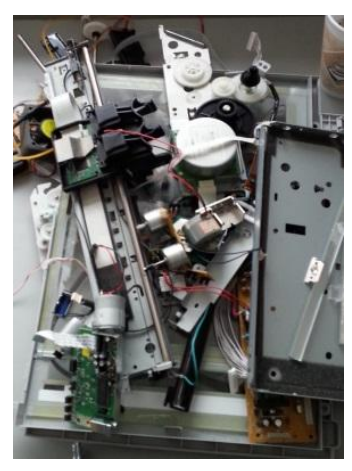

Figure 1: E-Waste process under computer control. The $3 \mathrm{D}$ printing is a process of making a three-dimensional solid object of virtually any shape from a digital model. Since it can instantly print parts or an entire product based on a designed 3D graphic, it brings a revolutionary way for professionals and hobbyists to create their innovative projects.

Building a 3D printer for education has been developed in recent years ${ }^{1,2}$. However, the prices of the devices are still pretty expensive compared to other educational devices. In this project, we try to develop the product based on the recycled electronic components as shown in Figure 1, which will make the product affordable for most educational institutions.

The second reason for us to develop the project in this way is to enhance people's awareness for environmental protection from e-waste. 
According to the U.S. Environment Protection Agency (EPA), the U.S. electronic waste is growing about 3 times faster than any other waste as roughly 300 to 400 million electronics are thrown out in the garbage. The problem occurs with the increasing processing powers and capabilities of computers and printers every year. Since obsolete electronics are no longer viable in businesses and institutions, they pose a security and productivity threat to the entire society. Especially, e-waste represents approximately $70 \%$ of America's toxic waste, which causes serious contamination of American soils. For example, a 3D printer requires valuable high powered stepper motors that would otherwise be thrown into a landfill. Therefore, designing 3D printer with e-waste can both cut product's cost and protect the environment where we are living.

\section{PRIMARY DESIGN ANALYSIS}

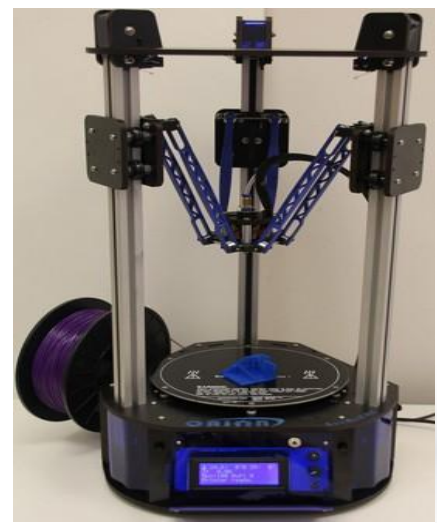

(a)

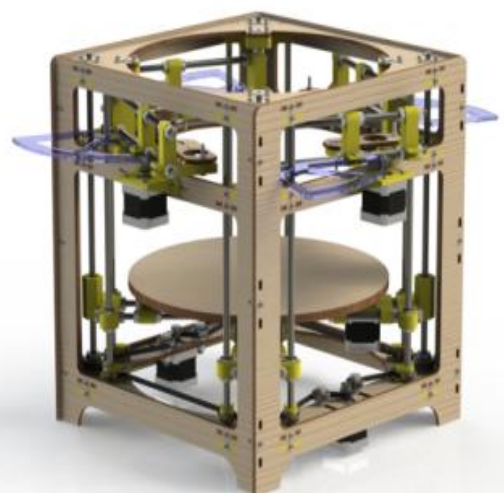

(b)

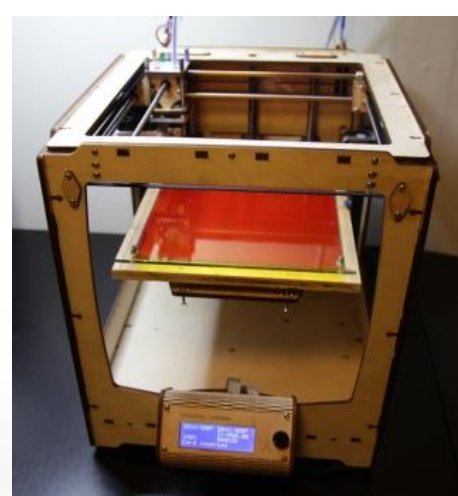

(c)

Figure 2: Picking 3D Printer Design (a) Delta (b) Polar (c) 2-D Fixed Bed

At the beginning of the design, we have collected three types of the printer prototype as shown Figure 2. They are delta, polar and 2-D fixed bed. After analysis of available parts and the difficulty of technique, we chose the 2-D fixed bed, which makes the design and troubleshooting easy.

\section{ENGINEERING REQUIREMENTS AND CONSTRAINTS}

For the designed 3D Printer, the requirements and constraints are (1) the dimension cannot exceed 20 in $\times 20$ in $\times 20$ in; (2) the maximum printing volume will be 8 in $\times 8$ in $\times 8$ in; (3) the voltage supply for the microcontroller must not exceed $3.6 \mathrm{~V}$; (4) all models that will be printed must be in .STL format no exceptions; (5) the filament for the extruder must be $1.5 \mathrm{~mm}$.

\section{SYSTEM COMPONENTS}

\subsection{Microcontroller}

The microcontroller is a Freescale FRDM-KL $25 Z^{3}$ which is compatible with an Arduino shield and has an open SDA for debugging purposes. The Freescale board is $48 \mathrm{MHz}, 128 \mathrm{~KB}$ Flash, 16KB SRAM, USB OTG (FS), 80 LQFP. 

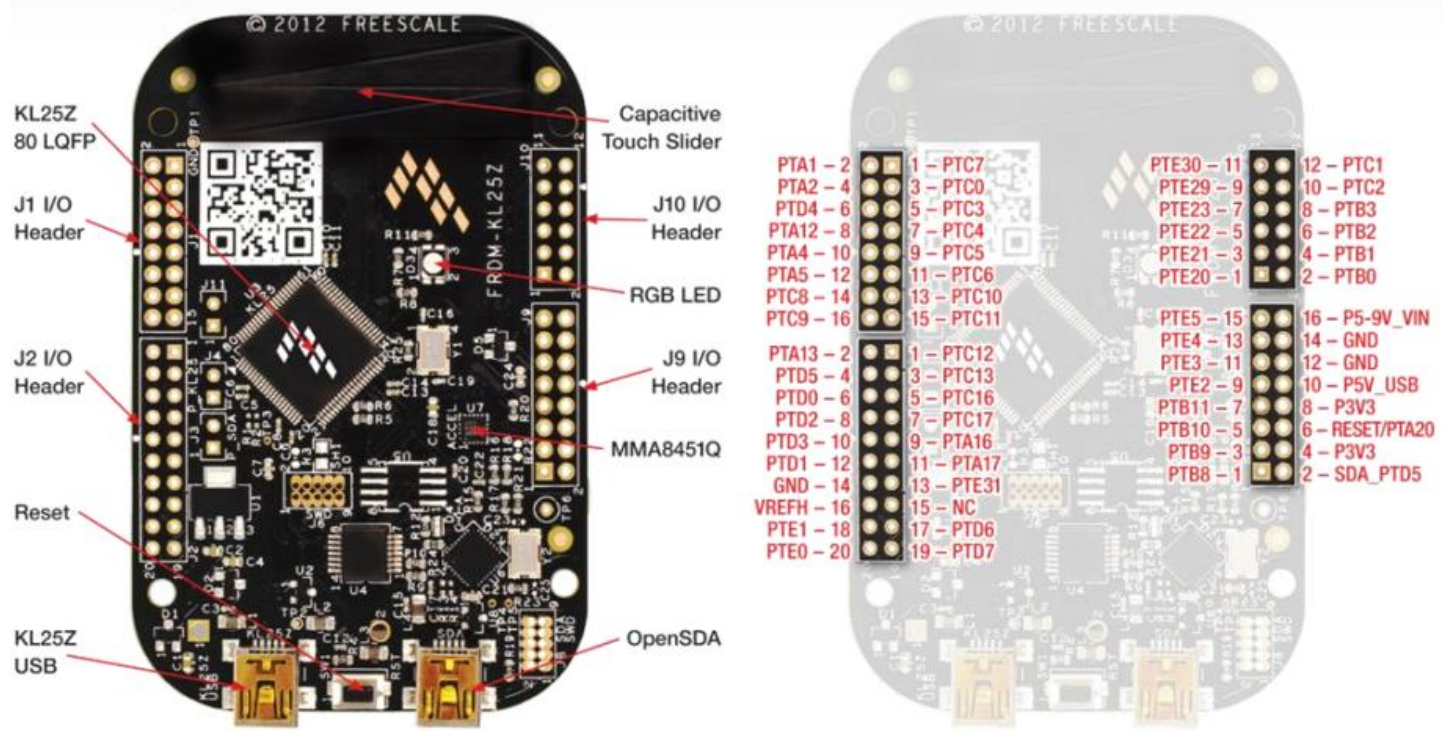

Figure 3: Freescale FRDM-KL25Z Pin Layout

\subsection{Stepper Motors}

The stepper motor used in the project is shown in Figure 4, which requires $12 \mathrm{~V}$ power supply and has $15 \mathrm{~N}-\mathrm{cm}$ torque for manipulation of the extruder ${ }^{4}$. Also, the motor with $1.8^{\circ}$ per step has four lead wires which are $31 \mathrm{~mm} \times 38 \mathrm{~mm}$ L. It's a bipolar stepper motor. Three different stepper motors are used for the manipulation of the extruder in three dimensional directions, and one additional stepper motor is used to control the filament feeding mechanism.

The stepper motor for the bed is also a $12 \mathrm{~V}$ stepper motor and has $100 \mathrm{~N}-\mathrm{cm}$. The bed stepper motor is coupled with a gear train for increased torque.

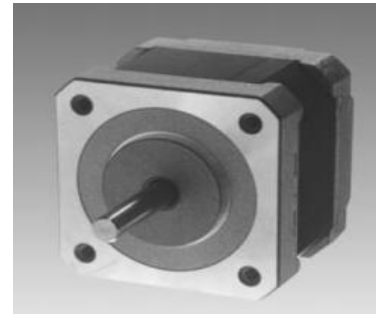

Figure 4: Stepper Motor

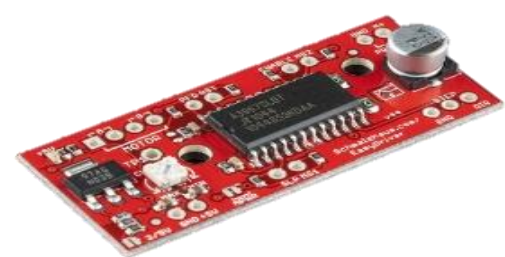

Figure 5: Easy Driver for Stepper Motor

\subsection{EasyDriver for Stepper Motor ${ }^{5}$}

For controlling the stepper motors, the EasyDriver - Stepper Motor Driver which uses an A3968 micro-stepping driver is applied (See Figure 5). The motor driver has the capabilities of driving a 4, 6, or 8 lead bi-polar stepper motors. It features an adjustable current control ranging from $150 \mathrm{~mA} /$ phase to $750 \mathrm{~mA} /$ phase allowing easy changes for dynamic projects such as this one. 
The usage is quite simple where one pin is used for direction and another is a rising edge detector for actual motor stepping.

\subsection{Smart Extruder}

The extruder is a MakerBot smart extruder that has an intake filament of $1.5 \mathrm{~mm}$ diameter, which is shown in Figure 6. The temperature for the extruder rises to $215^{\circ} \mathrm{C}{ }^{6,7}$ and has metallic fins before the heading head for faster cooling. Furthermore, the extruder is coupled with a temperature sensor.

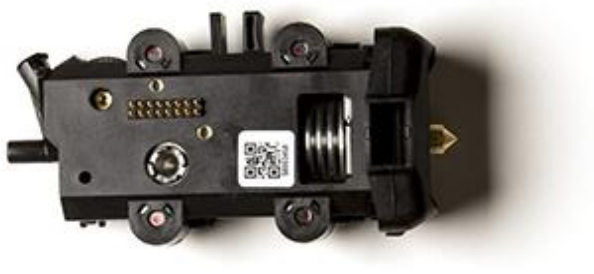

Figure 6: Smart Extruder

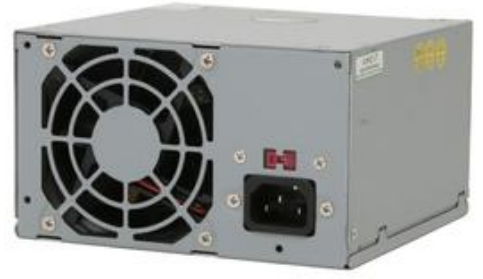

Figure 7: Dell 400W Power Supply

\subsection{Power Supply}

The power supply used is from a Dell computer which has the capability of supplying a maximum power of $400 \mathrm{~W}^{8}$. The power supply has an input of $100 \sim 240 \mathrm{~V} / 8 \mathrm{~A} / 50 / 60 \mathrm{~Hz}$ and output of $+3.3 \mathrm{~V},+5 \mathrm{~V}$, and +12 power rails.

\subsection{Fans}

The fans that are used are 4 inch diameter fans and one of the two fans is coupled with a mesh filter.

\section{SYSTEM DESIGN FROM E-WASTE}

\subsection{Chassis Construction}

The Chassis is made of wood with the dimensions of 20 in $\times 17.5$ in $\times 15.5$ in and will be held together by $1 / 8$ in wood screws. The design will be an open concept meaning that the $3 \mathrm{D}$ printer will have natural air circulation for cooling. An old scanner provided the perfect solution as the starting point for our printer bed.

Chassis construction is limited to what salvage e-waste is available. This project used half inch thick plywood pieces that were left over from a previous project. The main goal is to provide mounting points around the printer bed as well as the support to the extruder system. By measuring around the printer bed, an extra four inches was added onto the left and right of the printer bed. This is used for $3 / 8^{\text {th }}$ inch threaded rods to be arranged which allows for movement in the vertical direction. These rods were held in place by recycling a small plastic cylinder that was halved, semi-hollowed, and drilled onto the base of the chassis. The top of the rods was 
secured using two broken VEX ${ }^{\mathrm{TM}}$ motor covers that were also drilled to fit. Two extra support rods were added to govern precision as well as adjustment control. The completed chassis can be seen in Figure 8.

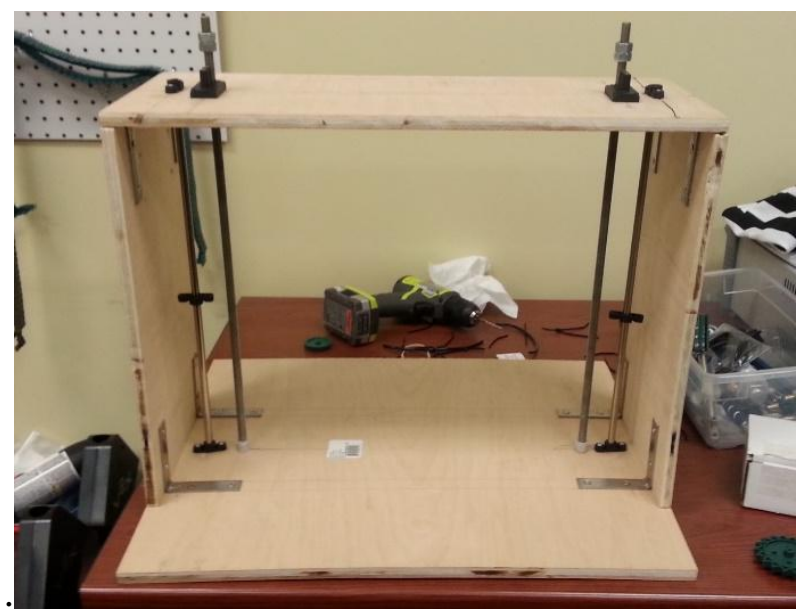

Figure 8: Completed Frame Construction

\subsection{One Dimensional Printing Bed}

During e-waste scavenging, an old scanner had all the components needed for the 3D printer design in one dimension. The scanner features a stepper motor coupled with torque gears, rod supports with bushings, a timing belt, and even an optical sensor which we centered as shown in Figure 9. This sensor is used later for defining the home position for the $3 \mathrm{D}$ printing process.

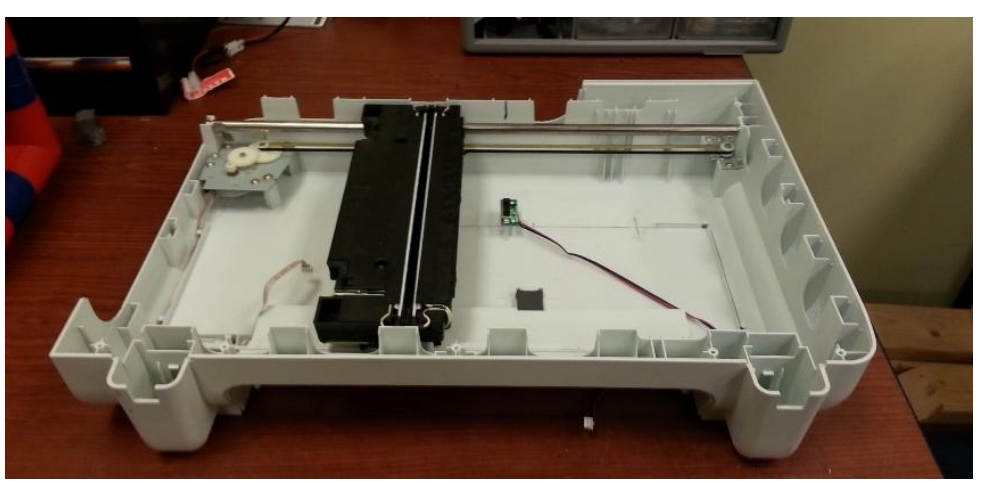

Figure 9: Salvaged Scanner Bed from E-waste

\subsection{Extruder System}

Recycling a normal printer yields the inkjet mechanism that was used for the horizontal direction in the project, which is shown in Figure 10. 


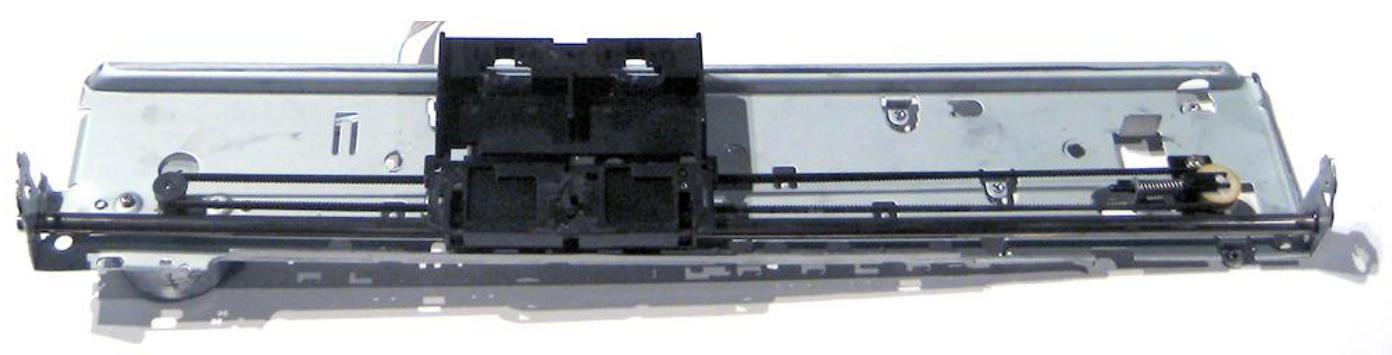

Figure 10: Inkjet mechanism

\subsection{The Designed 3D Printer System}

Figure 11 displays the designed 3D printer from e-waster. Since the 3D printer needs to be controlled in three dimensions, in order to discuss the control mechanism easily, we define the coordination as in Figure 12. The coordinate system discussed in the paper will follow the Cartesian plane. The bed moves in the $\mathrm{Z}$ direction while the extruder head moves in the $\mathrm{X}$ and $\mathrm{Y}$ directions.
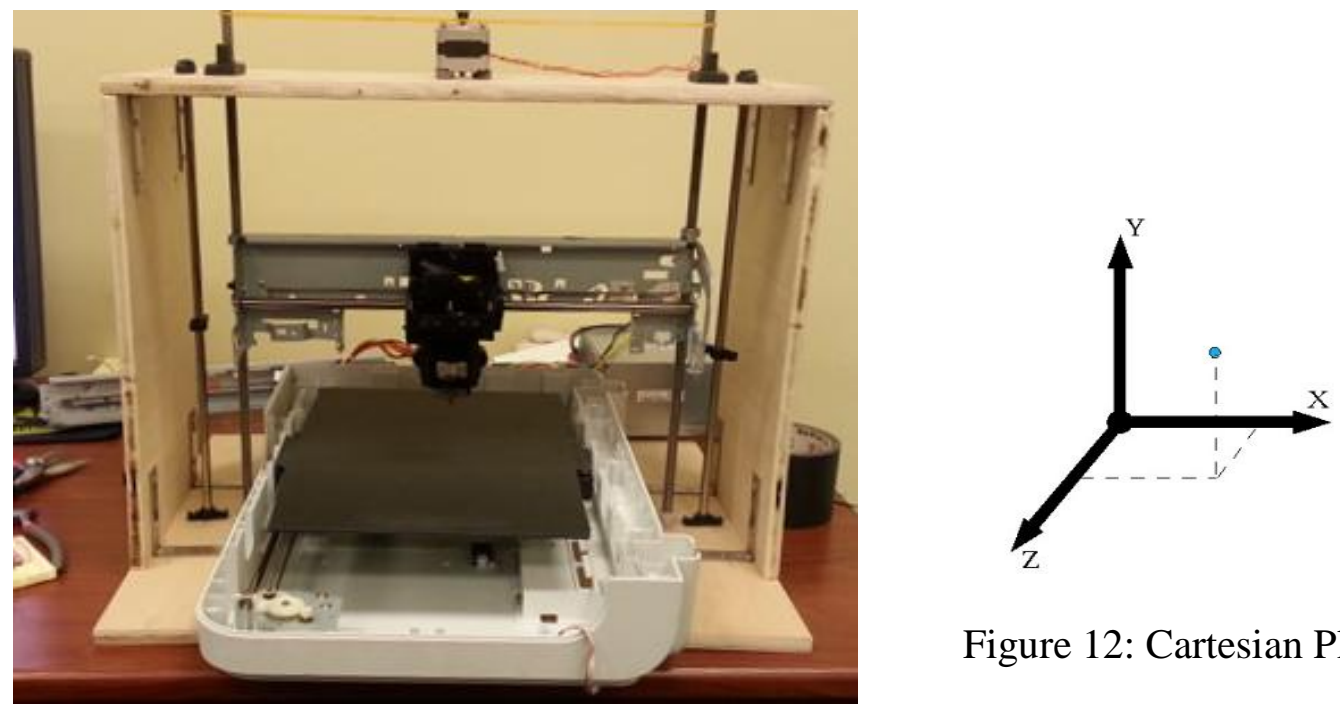

Figure 12: Cartesian Plane

Figure 11: Designed 3D Printer

We try to get enough stepper motors from used electronic devices. Unfortunately, today's printers use a combination of a normal DC motor with a timing belt and an optical encoder to save costs instead of using a stepper motor. However, after salvaging over ten printers, a stepper motor with a gear mount was found to match the timing belt already supplied by the inkjet mechanism. We swapped out the DC motor and installed the stepper motor and drilled onto the sheet metal for support screws. Then, we prepared four $3 / 8^{\text {th }}$ inch screw nuts to hold the mechanism in place. This covers the X-direction locomotion. For the Y-direction, we used the highest toque stepper motor recovered from an industrial sized laser printer which will spin the two threaded rods simultaneously via a timing belt. 
Finding an extruder is difficult, which may be added to the cost of replicating our project. We managed to find a MakerBot ${ }^{\mathrm{TM}}$ Smart Extruder that was heavily used and had reduced functionality. By viewing various MakerBot ${ }^{\mathrm{TM}}$ users' websites and conversing with other 3D printer enthusiasts, we managed to refurbish the extruder system with a heat gun and remove left over filament with compressed air. Then, we placed the extruder in the inkjet mechanism by carefully hollowing out the ink cartridges holders and securing it with screws.

A simple glass plate found from another scanner wrapped in masking tape was used as our printer bed. This is held onto the base of the Z-direction motor with some epoxy.

\section{Software PROGRAMMING}

\subsection{Slic3r Software9}

The Slic3r software is used to convert STL filer into G-code or SVG layers. This software is an open source which allows modifications and is compatible with many open source 3D printer's firmware for direct uploading capabilities. Also, slic3r can be customizable to fit the 3D dimensions and a specific bed size. Using 3D printing software, 3D models of various file types are converted into the code for the customized printer with a user defined printing volume and the stepping degree of the stepper motors.

\subsection{Control Program Design}

Unless the builder already owns one, a microcontroller may be the device which must be purchased. Recovering one from e-waste is extremely difficult and tedious to attempt. For us, we used the Freescale Freedom board (FRDM-KL25Z). We connected all the bi-polar motors (all of which are 4-wire configuration) onto the stepper motor drivers which are then controlled by the microcontroller. The whole project is powered by an old computer $400 \mathrm{~W}$ power supply that has the capabilities of providing $5 \mathrm{~V}, 12 \mathrm{~V}$ and $20 \mathrm{~V}$ power rails. The logic flowchart of our project is shown in Figure 12.

\section{Cost}

Table 1 lists the cost for the 3D printer built from E-waste.

Table 1: Cost for the designed 3D Printer

\begin{tabular}{|l|c|c|c|}
\hline Item & Quantity & Per Unit Cost & Cost \\
\hline Easy Driver Stepper Motor Driver & 4 & $\$ 10.00$ & $\$ 40.00$ \\
\hline Extruder* & 1 & $\$ 50.00$ & $\$ 50.00$ \\
\hline Temperature Sensor* $^{*}$ & 1 & $\$ 5.00$ & $\$ 5.00$ \\
\hline Microcontroller $^{\dagger}$ & 1 & $\$ 15.00$ & $\$ 15.00$ \\
\hline \multicolumn{2}{|r|}{ Total } & $\$ 110.00$ \\
\hline
\end{tabular}

* Optional if not found during e-Waste recycling.

${ }^{\dagger}$ Electronics hobbyist may already have one at their disposal. 


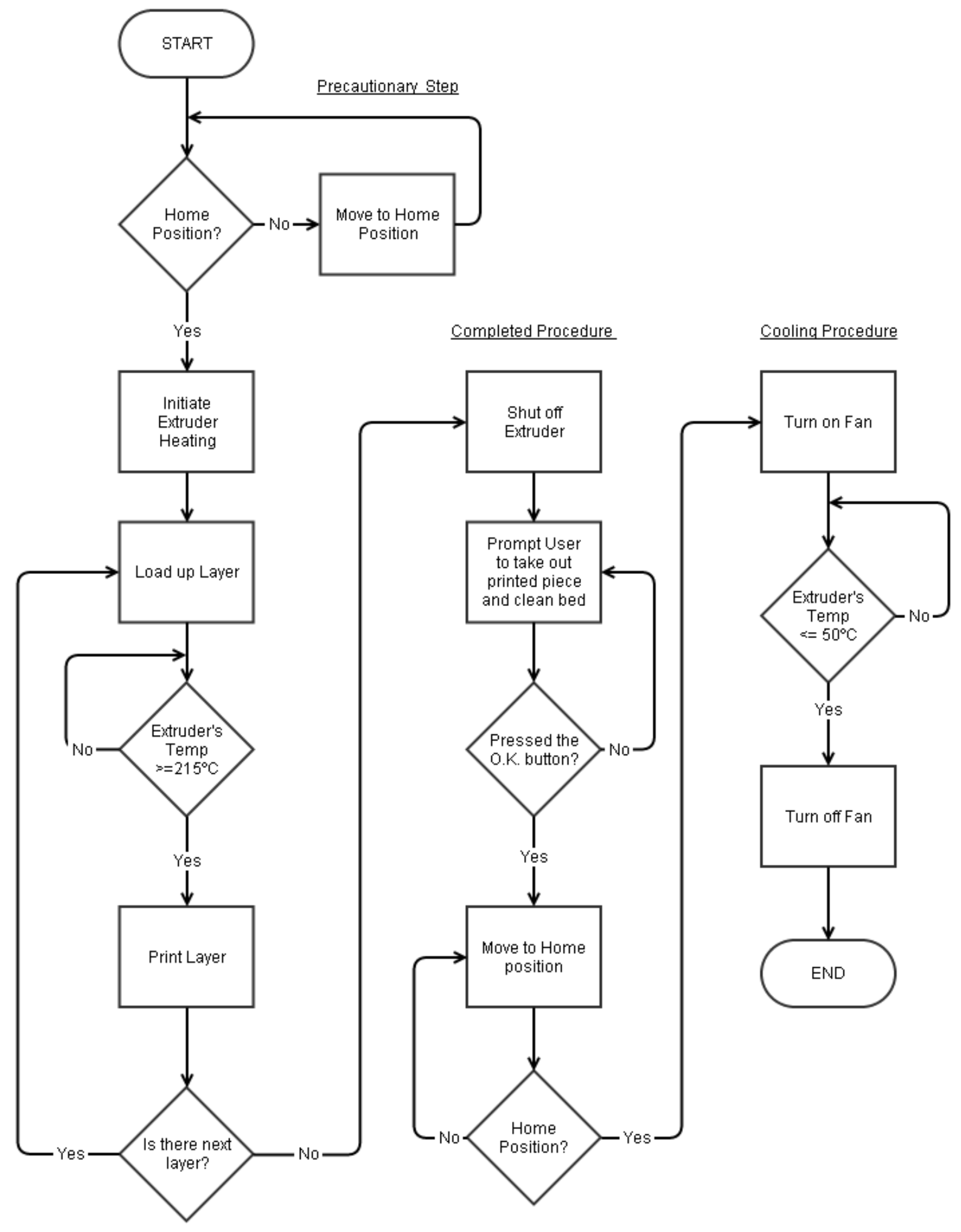

Figure 12: Flowchart for Printing Algorithm 


\section{CONSLUSION}

3D Printers are gaining popularity and becoming a necessity in educational institutions and industries. The reason why we chose to make a 3D printer from e-waste is mainly due to the fact that electronics with perfectly components are thrown out in our daily lives due to technology advancements. Therefore making a 3D printer from e-waste will be a suitable solution for hobbyists or students interested in learning how to innovate parts that they already possess. In fact, a 3D printer is expensive. This will also be a solution to saving money instead of wasting hundreds of dollars to purchase one. The 3D printer will not only be a learning experience for the ideal person and cheaper, it will also be an answer to the e-waste dilemma that we face in today's world.

\section{REFERENCES}

[1] R. Mercuri and K. Meredith, "An Educational Venture into 3D Printing", The 4th IEEE Integrated STEM Education Conference, March 8, 2014, Princeton, NJ.

[2] J. Gonzalez-Gomez, A. Valero-Gomez, A. Prieto-Moreno, M. Abderrahim, "A New Open Source 3D-printable Mobile Robotic Platform for Education", In Advances in Autonomous Mini Robots, Springer Berlin Heidelberg, 2012, pp 49-62.

[3] "FRDM-KL25Z: Freescale Freedom Development Platform for Kinetis KL14, KL15, KL24, KL25 MCUs." Freescale Freedom Development Platform for Ki|Freescale. N.p., n.d. Web. 10 Feb. 2015. http://www.freescale.com/webapp/sps/site/prod_summary.jsp?code=FRDM-KL25Z.

[4] "Stepper Motor Series SST42D", N.p., n.d. Catalogue. 10 Feb. 2015.

[5] "EasyDriver - Stepper Motor Driver." - ROB-13226. N.p., n.d. Web. 10 Feb. 2015. https://www.sparkfun.com/products/13226

[6] Fallon, Ray. "Let's Talk about the Smart Extruder." MakerBot. N.p., 29 Sept. 2014. Web.10, Feb. 2015. http://www.makerbot.com/blog/2014/09/29/makerbot-replicator-smart-extruder-designed-future-mind/

[7] "MakerBot MakerBot Support." MakerBot. N.p., n.d. Web. 10 Feb. 2015. https://www.makerbot.com/support/new/03 Replicator_Z18/Knowledge_Base/What Temperature Is my_Sma $\underline{\text { rt Extruder }}$

[8] "RepRage." - How Much Power Does a 3D Printer Use? N.p., n.d. Web. 10 Feb. 2015. http://reprage.com/post/39698552378/how-much-power-does-a-3d-printer-use

[9] Slic3r.org,. 'Slic3r - G-Code Generator For 3D Printers'. N.p., 2015. Web. 18 Feb. 2015. http://slic3r.org/ 